\title{
"Hacer de Chile una gran Nación". La Carretera Austral y Patagonia Aysén durante la dictadura cívico militar (1973-1990)
}

\section{"Make Chile a great Nation". The Southern Highway and Patagonia Aysén during the military civic dictatorship (1973-1990)}

\author{
Santiago Urrutia Reveco ${ }^{1}$
}

\begin{abstract}
RESUMEN
Recorrer la Carretera Austral constituye en la actualidad una de las principales razones para visitar la Patagonia chilena. Este artículo tiene como propósito estudiar el proceso de construcción de la Carretera Austral durante la dictadura cívico militar (1973-1990) desde una aproximación "más que humana". En este sentido, interesa analizar la agencia del camino y su impacto territorial. Desde esta base, y a partir de la revisión de material de prensa, declaraciones gubernamentales, memorias ministeriales, estudios técnicos y bibliografía especializada, se propone que el trazado en sentido longitudinal de la Carretera Austral implicó un particular proceso de reestructuración territorial en la Patagonia chilena que constituyó, en el período de estudio, una pieza importante de las transformaciones sociales y políticas del espacio austral y una de las claves territoriales de la organización autoritaria del país.
\end{abstract}

Palabras clave: Carretera Austral, Patagonia, Dictadura

\begin{abstract}
Traveling the Southern Highway is currently one of the main reasons to visit Chilean Patagonia. This article aims to study the construction process of the Southern Highway during the military civic dictatorship (1973-1990) from a "more than human" approach. In this sense, it is interesting to analyze the agency of the road and its territorial impact. From this base, and the review of press material, government declarations, ministerial reports, technical studies and specialized bibliography, it is proposed that the longitudinal outline of the Austral Highway implied a particular process of territorial restructuring in the Chilean Patagonia that It constituted, during the study period, an important piece of the social and political transformations of the southern space and one of the territorial keys of the authoritarian organization of the country.
\end{abstract}

Key words: Southern Highway, Patagonia, Dictatorship. 
“(...) el troncal en sí mismo es ya un fabuloso negocio: todo el territorio fluyendo por una misma línea" (Nicolás Richard, 2013)

En mayo de 1976, mientras se realizaban los estudios técnicos que habían sido encargados por el general Pinochet al Cuerpo Militar del Trabajo (CMT) y la Dirección de Vialidad del Ministerio de Obras Públicas (MOP) para definir el diseño del sistema caminero que debía unir terrestremente la Patagonia chilena al territorio nacional², el Secretario Regional de Obras Públicas de Aysén, Carlos Brunning, afirmaba que la estrategia vial regional se estructuraba en función de sacar los enclaves continentales hacia el mar mediante caminos transversales, pues "Es lo más lógico, lo más expedito para luego utilizar barcazas, transbordadores, ferry, etc, para viajar al norte"3.

Desde esta perspectiva, los caminos transversales tenían prioridad pues crearían cuatro grandes áreas de influencia con sus respectivos polos de desarrollo que luego se unirían, mediante un camino longitudinal y por mar, a Puerto Montt y el país. Coherente con esta estrategia, ese año había en Patagonia Aysén ${ }^{4}$ aproximadamente 1.177,8 km. de caminos, de los cuales 830,1 km. eran transversales, mientras que sólo $347,7 \mathrm{~km}$. correspondían al trazado longitudinal (Ministerio de Obras Públicas, 1986).

Dichos datos eran la constatación de una realidad histórica que estaba por cambiar: la orientación transversal (y transfronteriza) de la circulación en este territorio fue la norma no solo para el saber técnico y discurso político, sino que, sobre todo, de las prácticas cotidianas hasta bien entrado el siglo XX ( $y$ en algunos sectores incluso hasta en la actualidad) (Saavedra \& Mansilla, 2014).

De este modo, si la conformación e institucionalización "moderna" del territorio chileno es un proceso que, como sostiene Andrés Núñez $(2009,2012)$, coincide con su estructuración longitudinal (norte-sur, y viceversa), es decir, con su "verticalización", puede comprenderse por qué hasta incluso la segunda mitad del siglo XX este área que representa casi un sexto del territorio continental ${ }^{5}$ era todavía considerada "tierra de entremedio" (Bandieri, 2011) y, fundamentalmente, margen y frontera de la nación (Núñez et al., 2017).

Desde el punto de vista de los caminos, el territorio de Patagonia Aysén ha constituido una excepción, o más bien un obstáculo, al canon normativo de la circulación nacional, y por esto, por lo menos hasta la década de 1970 se ha considerado una "isla" puesto que en gran parte de su historia ha sido accesible solamente por aire o por mar, mientras que por tierra ha dependido del tránsito por territorio argentino ${ }^{6}$ (García, 1989; Van Schouwen, 1996).

Plan caminero que volvía a evaluarse luego de la aprobación del proyecto "Carretera Longitudinal Austral" de la Dirección de Vialidad en 1968 Buscando salida al mar. Intenso ritmo en obras camineras. (8 de mayo de 1976). El Diario de Aysén, p.1

De modo general, se entiende que la Patagonia chilena está compuesta por la provincia de Palena (parte austral de la región de Los Lagos), la región de Aysén y la región de Magallanes. Con Patagonia Aysén nos referimos a lo que actualmente son la región de Aysén y la provincia de Palena, área que atraviesa el Camino Longitudinal Austral. Si bien en la actualidad Palena es administrativamente parte de la región de Los Lagos, históricamente se reconoce como parte de la misma formación sociocultural con Aysén (Martinic, 2014). De hecho, para efectos técnicos, en la época del régimen autoritario esta área fue vista como una unidad administrativa para llevar a cabo el proyecto Camino Longitudinal Austral, aunque cada ente tuvo sus particularidades en el proceso de construcción del mismo. Traspaso. Palena a Aysén en materias viales (20 de febrero de 1982). El Diario de Aysén.

5 La Carretera Austral atraviesa la provincia de Palena (15.302 km2) y la región de Aysén (108.494 km2), es decir, corre y conecta una superficie de 123.796 km2, lo cual constituye un $16,354 \%$ de los 756.950 km2 de Chile continental.

6 En términos cotidianos, para saciar la necesidad de servicios de educación, salud, trabajo y alimentación el cruce hacia el lado argentino fue (y en muchos casos sigue siendo) constante, lo cual quedó reflejado en la configuración de una identidad sociocultural más "argentina" que 
En otras ocasiones ni siquiera se le reconoció. Por ejemplo, en un libro titulado Chile y sus caminos. Geografía de las comunicaciones del año 1971, la descripción del país y sus vías de comunicación termina en Puerto Montt, es decir, el último destino hacia el sur tanto del Ferrocarril que llegó en la primera mitad del siglo XX como de la carretera internacional Panamericana (Ruta 5) que arribó posteriormente (Naranjo, 1971).

Desde esta óptica, el territorio recorrido longitudinalmente por estas infraestructuras es el que se considera el Chile propiamente tal, en tanto "integrante del conjunto de comunicaciones modernas, en visión panamericana, como parte de las naciones del globo" (Naranjo, 1971: 21), quedando importantes áreas, como Aysén, excluidas de aquella representación. Es decir, comúnmente el territorio nacional se ha solapado con su estructura vial como si Chile existiera hasta el límite de su gran eje caminero longitudinal, como si hacer caminos fuera sinónimo de hacer nación.

En este sentido, coherente con el propósito de "hacer de Chile una gran Nación" anunciado por la Junta Militar en su primera Declaración de Principios tras el Golpe de Estado (Gobierno de Chile, 1974), la construcción de la Carretera Austral a lo largo del territorio patagónico adquirió gran relevancia tanto a nivel de las inversiones públicas como en la propaganda del régimen ya que, desde el punto de vista de las autoridades, en el área incorporada por el camino supuestamente “comenzará mañana sus albores el Chile nuevo, rico y pletórico de energías, que nuestros gobernantes ansían crear" (S/A, 1981: 11).

Profundizando el relato construido durante la dictadura (Polloni, 1982; Bascuñán, 1983; Von Chrismar, 1986; García, 1989), gran parte de la bibliografía referida al camino austral ha fortalecido, a partir de la descripción de los trabajos de construcción presentados como una constante lucha entre el humano y la naturaleza, un discurso heroico y trascendental en torno a la obra, su supuesto efecto geopolítico y modernizador, que tiende a legitimar no tan sólo la ruta, sino también al régimen autoritario (Peña, 1993; Van Schouwen, 1996; Krebs, 1997; Vásquez de Acuña,1999).

Por otro lado, trabajos más recientes se han alejado de estas visiones conservadoras enfocándose en las representaciones vinculadas a la obra y en los vínculos entre esta y su contexto político social (Espinoza, 2016; Urrutia, 2017; Rossetti, 2018; Urrutia et al., 2019). Sin embargo, ya sea mediante el énfasis positivista en las labores de construcción y sus principales responsables que muestra el primer enfoque o en las perspectivas constructivistas de las representaciones colectivas del segundo, ambos acercamientos tienen en común hacer del camino austral una consecuencia fuertemente determinada por la inteligencia y acción humana, encarnada en los altos mandos del régimen militar.

Sin subestimar la relevancia del contexto socioespacial y las dinámicas políticas desplegadas en este, el presente artículo tiene como propósito estudiar el proceso de construcción del Camino Longitudinal Austral (Ruta 7) en la Patagonia chilena durante la dictadura cívico militar experimen-

"chilena" y en relaciones de parentesco de uno y otro lado de la frontera (Baeza, 2009; Núñez, et al., 2017; Rodríguez, et al., 2018). En términos de circulación por territorio chileno, resulta claro que el transporte de carga para dar salida a la producción se realizaba casi exclusivamente a través de los puertos marítimos (Chaitén, Puerto Cisnes, Puerto Chacabuco), fluviales (Puerto Aisén, Puerto San Carlos, Puerto Nuevo, Puerto Alegre) o lacustres (Puerto Cárdenas, Puerto Ramírez, Puerto Ibáñez, Chile Chico, Puerto Guadal, Puerto Bertrand, Puerto Herradura). Asimismo, particularmente esta zona contenía una concentración de pequeños aeródromos relativamente mayor a la de otras áreas del territorio nacional: en Chaitén, Puyuhuapi, Balmaceda, teniente Vidal (Coyhaique), Puerto Aysén, Chile Chico, Cochrane. 
tando con un enfoque teórico alternativo sobre la base conceptual del "retorno material" (material returns) y la perspectiva "más que humana" (more than human) en el área de la geografía (Whatmore, 2002, 2006; Panelli, 2010; Greenhough, 2014; Choi, 2016).

Desde este marco teórico, lo que más precisamente interesa acá es analizar una manera particular que tuvo la Carretera Austral de agenciar el territorio patagónico en el período de estudio. Para ello, metodológicamente, la materialidad del camino en su proceso de construcción a lo largo de los casi veinte años de régimen es comprendida como registro del modo en que el camino "expresa" sus capacidades (De Landa, 2000, 2011; Bennett, 2010) e imprime nuevas dinámicas políticas al territorio gracias al tipo de circulación que ella encauza (Vallaux, 1914; Richard, 2013).

En este sentido, y a partir de la revisión de material de prensa, declaraciones gubernamentales, memorias ministeriales, estudios técnicos y bibliografía especializada, se propone que la Carretera Austral implicó un particular proceso de reestructuración territorial en la Patagonia chilena que constituyó, en el período de estudio, una pieza importante de las transformaciones sociales y políticas del espacio austral y una de las claves territoriales de la organización autoritaria del país.

\section{El Camino Longitudinal Austral: “la mayor obra pública del siglo XX"}

La Carretera Austral (o Camino Longitudinal Austral) es una ruta de aproximadamente 1.240 $\mathrm{km}$. de largo que atraviesa verticalmente la Patagonia chilena entre Puerto Montt (Región de Los Lagos) y Villa O'Higgins (Región de Aysén), es decir, aproximadamente entre los $41,8^{\circ}$ hasta los $49^{\circ}$ de latitud sur, área conocida también como Patagonia Norcentral o Patagonia Aysén. Las faenas de construcción en torno a la obra vial llevan casi medio siglo y todavía siguen en ejecución. En cuatro décadas han sido invertidos en ella más de US\$1.136 millones razón por la que es catalogada como "La mayor obra pública del siglo XX en Chile"7.

Si bien, como su nombre sugiere, parte importante de su trazado es longitudinal, en realidad forma parte de un sistema vial complejo constituido por el mencionado trazado 'troncal' que corre en dirección norte-sur, al que se conectan una serie de rutas transversales ('ramales' que, en su mayoría, son también caminos internacionales o transfronterizos), sendas de penetración, puentes y transbordadores que, en conjunto, son la más importante red de comunicación y transporte local en la actualidad.

Sin embargo, durante la mayor parte del siglo $X X$, debido principalmente a la ausencia de una ruta longitudinal, esta zona fue accesible principalmente por mar y por aire, mientras que por tierra sólo era posible hacerlo a través del mucho más complejo sistema de rutas argentinas que extendía su influencia a través de los caminos transversales dispersos en el lado chileno. Cuestión que, en el contexto de la dictadura chilena y de las tensiones limítrofes con Argentina que dificultaron

Carretera Austral suma inversión de más de US\$ 1.136 millones en cuatro décadas. (14 de febrero de 2016). El Mercurio. Disponible en: http:// www.economiaynegocios.cl/noticias/noticias.asp?id=226428 
el tránsito llamado 'Chile a Chile', le implicó ser considerada una "isla" en términos geopolíticos y de conectividad (García, 1989; Van Schouwen, 1996).

Pese a que había comenzado a construirse en la década de 1960, durante la dictadura se convirtió en una de las obras públicas más representativas del período. En poco más de una década se llevaron a cabo importantes avances del camino gracias a la acción conjunta del CMT, la Dirección de Vialidad del MOP, el Programa de Empleo Mínimo (PEM) y empresas constructoras privadas gracias a licitaciones realizadas por el aparato público.

Para 1988 se había inaugurado la conexión longitudinal entre Puerto Montt y Cochrane, es decir, cerca de mil kilómetros de camino (sin contar trazados transversales y considerando tres transbordos: seno Reloncaví, canal Comau y fiordo Reñihué) que constituye el grueso de la actual infraestructura.

Este año los números oficiales indicaban una Red Vial de aproximadamente $2.400 \mathrm{~km}$ que incluían el trazado longitudinal más los caminos transversales, y la construcción de 118 puentes definitivos que sumaban una longitud total de 4.720 metros lineales. Entre 1973 y 1988 se habían invertido $\$ 37.500 .000 .000$ pesos de la época y se consideraba que el avance físico representaba el $86 \%$ de lo estipulado (MOP, 1988). Con lo cual, la inversión pública para su construcción fue de las mayores del período después de las obras del Metro en la ciudad de Santiago y la inversión para la construcción de la central hidroeléctrica Colbún-Machicura (Rojas, 2000)ํ․

Sumado a estas cifras, autoridades y medios de comunicación oficiales afirmaron que la Carretera Austral era el "resultado de una iniciativa que es obra exclusiva del gobierno militar que preside el general Augusto Pinochet Ugarte"10, y, coherente con esto, pasó a denominarse -informalmente al menos- Carretera Austral "Presidente Pinochet". En este sentido se consideró "una de las realizaciones más importantes de nuestro actual gobierno y, sin duda, la obra predilecta de S.E el Presidente de la República (...) debido a su enorme trascendencia geopolítica" (Von Chrismar, 1986: 44) o como "el más importante de los proyectos de esta naturaleza que se hayan realizado en el presente siglo" (García, 1989: 64).

Desde este punto de vista, el Camino Longitudinal Austral era presentado como una de las principales obras de infraestructura para "hacer de Chile una gran Nación", ya que supuestamente influiría en cuestiones claves como el fortalecimiento de la soberanía en espacios considerados fronterizos, el fomento al poblamiento de "espacios vacíos", la integración física y articulación territorial, la defensa militar, la circulación de reglamentos, mandos y autoridades, el desarrollo y explotación de recursos estratégicos, entre otros. Con lo cual debía "enorgullecer no sólo a nuestro

Así se denominó al trayecto que debía hacerse para ir por tierra hasta Patagonia Aysén. Tradicionalmente para llegar a esta área se "salía" del territorio chileno por un paso internacional ubicado más al norte, generalmente, por el "Paso Cardenal Samoré" (Osorno - Villa La Angostura) y se volvía a "entrar" por cualquiera de los pasos hacia territorio chileno. El camino a Aysén. (15 de febrero de 1979). El Diario de Aysén, p.3.

9 A partir del denominado "retorno a la democracia" las actividades de construcción caminera han seguido avanzando en la zona austral. A fines de la década de 1990 el trazado alcanzó el objetivo de Puerto Yungay, y poco tiempo después, a Villa O’Higgins que constituye la localidad más austral conectada al camino. Actualmente, el CMT y Vialidad se encuentran realizando trabajos de extensión en el linde de Aysén con Magallanes, más otros trabajos de consolidación de caminos y trazados transversales. Para el futuro se proyecta que la conectividad alcance hasta Puerto Natales (Magallanes) completando una longitud total aproximada de 2.175 kilómetros, que permitiran la integración vial definitiva de todo el territorio nacional.

10 Mañana en Cisnes. S.E visitará las obras del longitudinal. (6 de febrero de 1978). El Diario de Aysén, p.3. 
supremo gobierno que la resolvió, planificó e impulsó, sino a todos los chilenos ya que satisfacen necesidades vitales de desarrollo y de seguridad nacional" (Von Chrismar, 1986: 44).

\section{Caminos y circulación}

Según Sarah Whatmore, tres virajes caracterizarían el descentramiento de lo humano, o más precisamente, el "retorno" a lo material en la geografía: del discurso a la práctica, es decir, la relocalización de la agencia social en las prácticas y performances más que en los discursos (Whatmore, 2006: 604); del sentido al afecto: "desde lo que las cosas significan hacia lo que las cosas hacen" (604) y hacia un enfoque "más-que-humano" que reconozca la agencia de lo no humano (orgánico o inorgánico) para comprender la co-fabricación sociomaterial del mundo. En suma, para Whatmore es importante destacar que hay tanto una multiplicidad de agencias y también de subjetividades, por cuanto estas se definirían no por una supuesta vida al interior del alma (humanismo), sino en el mundo de las prácticas cotidianas concretas. En este sentido, este "nuevo materialismo", sería ontológicamente distinto a toda la tradición materialista precedente (marxismo incluido).

Los enfoques más que humanos en geografía proponen renovadas formas de comprender las dinámicas tejidas entre los tradicionales binarismos del pensamiento moderno occidental, especialmente, entre lo humano y no humano, conceptualizando a estas últimas entidades (animales, plantas, infraestructuras, objetos, etc) como agentes creativos implicados en la producción espacial (Greenhough, 2014), en dinámicas relacionadas con la naturaleza y la ecología política (Choi, 2016) o en problemáticas propias de la geografía social (Panelli, 2010).

Dentro de estas últimas, dadas las nuevas condiciones de la realidad contemporánea, la movilidad y las comunicaciones constituyen temáticas centrales y centros de "experimentación" para los nuevos "giros" y teorías que han ido emergiendo (Sheller \& Urry, 2006). En este sentido, los caminos, una de las principales infraestructuras para la movilidad terrestre, ha sido objeto de las nuevas conceptualizaciones.

Según Bonelli \& González (2016), para saber qué es un camino, debemos explorar lo que el camino hace y sus capacidades. Es decir, poner al camino en el centro de la indagación e interrogar sus diversos agenciamientos.

De este modo, lo primero que sabemos sobre los caminos es que ellos movilizan. Más bien, por ahí se mueven de un lado a otro, cosas, personas, ideas, recursos, enfermedades, crisis y un sinnúmero de fenómenos. Tim Cresswell ha acuñado la noción de "constelaciones de movilidad" para comprender la articulación entre patrones de movimiento físico, representaciones sociales sobre el movimiento y las prácticas de movilidad que varían histórico-espacialmente y que se encuentran implicadas en procesos de producción de poder y relaciones de dominación (2010).

En este sentido, según Cresswell, existen tres niveles de cuestionamiento para el análisis de la movilidad. En primer lugar, ¿quién/qué se mueve más lejos o rápido?, luego, ¿Qué narrativas se construyen alrededor de la movilidad? Y, por último, ¿cómo es vivenciada esa movilidad? Asimismo, entre las preguntas clave para comprender acertadamente la dimensión política que tiene la movilidad destaca: "¿qué ruta toma?". Es sobre esta última cuestión que nos interesaría profundizar. 
Los caminos, en tanto canales que encauzan la movilidad implicarían, según Cresswell, el aspecto político vinculado al control y normalización de la misma mediante la "producción de una movilidad correcta" (Cresswell, 2010: 24-25). Una normalización que no queda restringida a las personas y cosas que se mueven, sino que también al espacio que atraviesan, desplazando así la atención puesta en los efectos materiales y simbólicos que los sujetos sociales producen sobre los caminos, a la capacidad que tienen las rutas, como todo objeto, de accionar y modificar el mundo.

En este sentido, resulta útil y necesario "pensar a través de las cosas" (Henare et al., 2007) y reconocer la "vitalidad" de lo material" (Bennett, 2010). Es decir, la capacidad que tienen ya sean los objetos con los que interactuamos cotidianamente (celulares, computadoras, relojes, bicicletas) o, como en este caso, infraestructuras que abarcan grandes superficies (carreteras, represas, parques eólicos), no solo de "servir" a las prácticas humanas, sino que de actuar como "fuerzas con trayectorias, propensiones o tendencias propias" (Bennett, 2010: viii), y reconocer en esas fuerzas particulares, implicancias y efectos políticos.

Pero los caminos no tan solo actúan, sino que también se expresan ${ }^{12}$ (De Landa, 2006). En este sentido, pueden ser considerados también como documentos o archivos que nos informan sobre diversas dinámicas del territorio que atraviesan y configuran. Y lo primero que nos dirían es que "la fenomenología del camino no se agota en los conceptos de 'vialidad' o 'red de comunicaciones' (Richard, 2013: 51)" que tendrían en común la definición estatal y hegemónica de los caminos, es decir, que son producto de la acción programada de un poder monopólico y centralizado (por ejemplo, la Vía Romana, la Ruta de la Seda china, el Camino del Inca).

Si bien nuestro trabajo se concentra precisamente en aquellos caminos de definición estatal, y más aún, durante un régimen autoritario, nos interesa esta perspectiva porque devela que, más allá de estos caminos normados hay "otros" caminos (y movilidades) que existen, están ahí, pero que a través de diversos procesos (técnicos, legales, económicos) quedan subordinados e incluso invisibilizados por aquella red vial oficial, hegemónica.

¿Qué áreas merecen ser conectadas según los caminos?, ¿Qué sentido de circulación encauzan?, ¿A qué velocidad y qué precauciones tomar para transitar en determinadas vías implican las características materiales de las mismas? Son algunas de las cuestiones que el énfasis en la expresividad o agencia del camino puede abordar.

Según Brian Larkin el concepto moderno de camino emerge durante el período de la llustración como mecanismo de control del tiempo y la circulación, por lo que es integral en la organización

\footnotetext{
Según Jane Bennett la materialidad es más que la materias prima y el producto del trabajo humano, así como también es más que una representación o manifestación simbólica de los procesos socioproductivos. Tiene su propia creatividad y vitalidad, reconoce una participación más activa a las fuerzas no humanas y una capacidad de producir efectos políticos, de control, de orden, que es irreductible a los significados o agendas humanas (Bennett, 2010).

12 Para Manuel De Landa la expresividad de la materia se refiere a la capacidad que tiene lo no humano, ya sea orgánico como inorgánico, de crear o dar origen a formas sin necesidad de agencias humanas que se las impongan. A partir de un estudio de los más diversos fenómenos geológicos, biológicos, físicos, climáticos De Landa muestra cómo la "expresividad" es una forma de afectar, de hacerse presente y comunicar sin necesidad de un lenguaje (2000). Una expresividad, por tanto, material, no simbólica donde la noción de "intensidad" cobrará protagonismo: "Las diferencias de intensidad están ahí en la producción de expresión, en la producción de la expresividad de la naturaleza. Cuando los animales territoriales crean un territorio lo que establecen es una posesión de ciertos recursos naturales que también son diferencias de intensidad, en este caso diferencias de concentración de ciertos alimentos, semillas, hojas o de proyección" (2011).
} 
de los mercados económicos y el concepto de progreso elaborado a partir de entonces (2013: 332). Desde su punto de vista, la acción de los caminos no se reduce únicamente a lo material, sino que también se desenvuelve en el nivel de los afectos y sensibilidades cotidianas. De este modo, los caminos son protagonistas del "fetichismo infraestructural" propio de la modernidad al movilizar una importante capacidad de "encantamiento" (Harvey \& Knox, 2012) vinculando ideales generales como los de modernidad o justicia con las prácticas cotidianas (Masquelier, 2002; Dalakoglou, 2012).

Los caminos trabajan, por tanto, en múltiples niveles. Tanto en el plano de las relaciones interestatales, subnacionales como las locales y cotidianas donde afectan y performatean experiencias sensoriales y otras vinculadas al poder (Zunino et al., 2017). En cada uno de estos niveles y desde el punto de vista de la materialidad de las vías terrestres de comunicación, la circulación es uno de los fenómenos más expresivos de los caminos, es decir, una de las maneras más evidentes y políticamente significativas que tienen las rutas de agenciar el territorio. En este sentido son, siguiendo a Larkin, verdaderas "arquitecturas para la circulación" (Larkin, 2013).

En su capítulo "La circulación" del libro El suelo y el Estado publicado a principios del siglo XX, Camille Vallaux sostiene la tesis de que la circulación ha sido comprendida tradicionalmente como un fenómeno económico, es decir, "como un desplazamiento de productos necesitados a la vez por la desigualdad productiva de las regiones del globo y por el desenvolvimiento de las necesidades de los hombres" (1914: 265), pero en realidad la circulación, según su propuesta, constituye fundamentalmente un "fenómeno político" y, específicamente, muy asociado a la acción y configuración del territorio y el Estado.

Desde su punto de vista, las vías terrestres estatales contribuyen concretamente a reforzar una política característicamente uniformadora. Pero ¿de qué modo? Según Vallaux, los caminos que se adaptan de mejor forma al suelo buscando las soluciones más sencillas son típicamente las vías económicas ya que estarían destinadas "a facilitar el cambio y el paso de los productos" (1914: 289), en cambio, los caminos que se edifican por terrenos difíciles muestran de buen modo que su utilidad principal es "neutralizar las tendencias centrífugas de territorios y de grupos de hombres todavía poco habituados a vivir juntos" (1914: 291). En este sentido operan como verdaderas "líneas de poder estratégico" que, en su búsqueda por sortear los "obstáculos" del terreno van configurando un sistema vial lo más recto, sencillo y corto posible que, en definitiva, "simplifica la geografía del Estado y transforma los valores relativos de las zonas de diferenciación" (1914: 308). De este modo demuestra que los caminos activan operaciones políticas fundamentales vinculadas al control y la jerarquización territorial.

Ciertamente existe toda una tipología de caminos (menores, "de penetración", senderos, huellas) que escapa y funciona como línea de fuga respecto de estos sistemas viales de control (Richard, 2013), pero por lo mismo, al menos desde la aparición de los Estados modernos uno de los principales problemas de gobierno lo ha constituido el de la circulación (Elden, 2007; Usher, 2014). Concretamente, la vigilancia de los caminos (Pasquino, 1991; Virilio, 2006) y de aquellos dispositivos que permiten "la irrigación de todo el cuerpo social de los efectos de poder llegando hasta sus más ínfimos resquicios" (Foucault, 1980: 18). En este sentido, la circulación en tanto fenómeno político y forma de expresividad de los caminos, es también, objeto de deseo y control de los aparatos de Estado. 


\section{¿Del "país de las cuencas" a territorio moderno?}

\section{Patagonia Aysén, territorio transversal}

Al realizar un paneo histórico a los caminos de Patagonia Aysén, la primera conclusión evidente es que sus rutas han hecho posible la preponderancia durante más tiempo que en otras partes del territorio nacional de una circulación transversal (y transfronteriza) propia del "país de las cuencas".

Según Andrés Núñez (2012), el "país de las cuencas" se refiere a una formación territorial "múltiple y diversa" que fue predominante en Chile hasta el siglo XIX. Su principal característica fue que su "sentido espacial se encauzó y canalizó en una posición oeste-este (y viceversa) a partir de cada cuenca o región fluvial" (Núñez, 2012: 3), es decir, estaba estructurado en torno a una circulación "horizontal en contraposición a la que posteriormente se impondrá, y que se mantiene hasta hoy, cuyo eje será vertical, es decir, de norte a sur o viceversa" (Núñez, 2012: 3).

Esto último resulta relevante para nuestro planteamiento puesto que, según Núñez, cada "cuenca" produjo modos de vida y circulación particulares asociados a dicha orientación espacial que, por otra parte, entorpecían el proyecto de homogenización y unificación territorial del Estado nación en formación. Dicho proceso de institucionalización de todos modos fue normado por diversos dispositivos a lo largo del siglo XIX siendo la construcción del Ferrocarril uno de los más importantes en tanto desdibujó el "país de las cuencas" y lo reestructuró longitudinal o verticalmente "con Santiago como órgano principal de centralidad" (Núñez, 2012: 6).

En este sentido, se puede sostener que para la historia territorial del Estado chileno modernizar es verticalizar (Núñez, 2009). Desde este punto de vista, como decíamos, la configuración espacial patagónica constituyó uno de los últimos resabios de la lógica "de las cuencas", excéntrica respecto de la norma o doxa territorial impuesta. Por ello, hasta la segunda mitad del siglo XX es un territorio no solamente marginal (Núñez, et al., 2017), sino que todavía "horizontal" o "transversal" así como "binacional" o "transfronterizo" desde el punto de vista de los caminos y la circulación (Baeza, 2009; Saavedra y Mansilla, 2014; Rodríguez et al., 2018).

Según Baldo Araya, la otra gran característica de los caminos de Aysén sería el rol político que han jugado. Para este cronista local la historia de los caminos locales comenzó abruptamente, ya que, en medio de los conflictos limítrofes de fines del XIX y principios del XX con Argentina, se consideró necesaria la configuración de "testimonios" o "pruebas palpables" que dieran cuenta de una ocupación efectiva ${ }^{13}$.

Una de estas "pruebas palpables" fue el eje transversal Puerto Aysén - Coyhaique que constituye hasta la actualidad una de las principales vías de circulación austral ${ }^{14}$. El origen de esta ruta se remonta a 1901 cuando la Comisión Chilena de Límites impulsó los primeros trabajos para abrir

\footnotetext{
Los caminos que reclamaron nuestros viejos. (5 de octubre de 1981). El Diario de Aysén.

14 Este camino atraviesa transversalmente el sector centro de Aysén. Originalmente conectaba a Coyhaique en la planicie oriental con Puerto Aysén en el litoral mediante un trazado aproximado de $65 \mathrm{~km}$. Actualmente el camino se ha extendido tanto hacia el oeste, a Puerto Chacabuco, debido al embancamiento de la bahía de Puerto Aysén provocada por la quema de amplias de superficie de bosques para implantar la ganadería en la primera mitad del siglo XX, y también hacia el este, hasta el poblado fronterizo de Balmaceda, incrementando su longitud 135 kilómetros.
} 
una senda cuyo objetivo principal era demostrar a Thomas Holdich, árbitro británico encargado de dirimir el conflicto fronterizo, que la nación chilena estaba presente en esa zona.

En sus extremos surgieron las ciudades más grandes y pujantes; a su orilla se instaló la oficina central de la Sociedad Industrial de Aysén, la gran propietaria y productora a la que el Estado le había regalado miles de hectáreas para poblar y explotar la zona, y además empalmaba con una de las principales vías de comunicación patagónica que se extendía hasta la ciudad de Comodoro Rivadavia en el litoral atlántico. Pese a esto, su construcción fue lenta e interrumpida, tanto así que su consolidación todavía no había sido completada para la dictadura.

La preponderancia de esta circulación horizontal y transfronteriza fue coherente no sólo con la circulación cotidiana sino también con la óptica institucional externa a la región, tal como en la década de 1930 expusiera el ingeniero Fernando Sepúlveda Veloso:

Por la configuración geográfica, la provincia de Aisén no necesita un camino longitudinal: le basta un solo trazado de caminos transversales que estén en estrecha relación con los puertos de embarque y desembarque de productos de la región: maderas, lanas, etc (...) Todo este trazado de caminos transversales dejarían a Aisén en condiciones de comunicarse sin necesidad de pasar al lado argentino, como actualmente se hace, ocasionando molestias tanto a los chilenos como a las autoridades argentinas (citado en Mansilla, 1946: 114-115).

En directa relación a la relevancia que tenía en la época el mencionado tránsito transfronterizo, una década más tarde, el Comité Pro Adelanto de Aisén en 1942 señalaba que: "Hay zonas extensas que sólo se comunican con Puerto Aisén a través de los caminos de la República Argentina" lo que supuestamente ocasionaba "serios problemas y perjuicios de la economía pública y privada" (citado en Bascuñán, 1984: 94).

Otro eje transversal importante para la circulación austral previa construcción del camino longitudinal, fue el que unía el poblado fronterizo de Palena con Chaitén hacia el sector norte. El interés primero en construir dicho camino respondió también a cuestiones políticas vinculadas a las tensiones limítrofes con Argentina, específicamente los problemas suscitados en torno a los hitos 16 y 17 en la década de 1950. Consecuentemente, toda su construcción quedó encargada al Ejército, por medio del Servicio Militar del Trabajo (actualmente CMT) y las faenas se llevaron a cabo entre 1954 y 1960 de manera simultánea en distintos frentes debido a las particulares características del sector y el apuro (geo)político de concretar la obra lo antes posible.

Coherente con dicha estructuración vial transversal, la Dirección de Vialidad en la década de 1960 señalaba que "Las rutas naturales de esa región atravesada por profundos ríos y cañadones transversales, son la aérea y la marítima, con la complementación de caminos transversales", por lo que según el organismo técnico "Es el mejoramiento de estos medios a los que deben tender los esfuerzos que se pueden aplicar en esa región y no a soluciones impracticables, geográfica y económicamente"15.

\footnotetext{
Esta fue la respuesta que recibió en la década de 1960 Baldo Araya de parte de la Dirección de Vialidad del Ministerio de Obras Públicas luego de que en calidad de Regidor de la ciudad de Coyhaique iniciara una campaña pública cuyo propósito era convencer a las autoridades centrales de la construcción de un camino longitudinal para la unión terrestre de la Patagonia con territorio nacional. Véase: El sueño por una carretera (tercera parte). (2 de agosto de 1978). El Diario de Aysén, p.3.
} 
Como resultado, para inicios de 1970 las dos vías de circulación más representativas de esta zona eran los mencionados ejes Chaitén - Palena y Coyhaique - Puerto Aysén: ambos encauzaban horizontalmente el territorio uniendo el mar con el interior siguiendo el sentido "natural" de la región. Sin embargo, ambos constituyen también casos relativamente excepcionales ya que la mayoría de los demás caminos de la época tenían tan solo un extremo, una pequeña parte de su trazado, dentro del territorio chileno.

Como se viene marcando, la gran característica de los caminos de esta zona antes del Golpe no es solamente su transversalidad, sino, en la práctica, su carácter internacional: del lado chileno nacían en algún punto cercano a la frontera, pero crecían y se desarrollaban en territorio argentino y en su mucho más avanzada red de caminos.

En estricto rigor, no es que conectaran Argentina con Chile, sino que en realidad "salían" de Chile "hacia" Argentina. Sustraían el flujo chileno de la Patagonia para expandirlo en la vertiente argentina: del lado oriental, una red de caminos, mayor acceso a servicios de salud, educación, alimentación, posibilidades de trabajo y un territorio para recorrer, del poniente, prácticamente una calle sin salida.

Concretamente, de la decena de caminos transversales existentes a principio de los setenta, al menos nueve eran a su vez pasos fronterizos y la mayoría de los asentamientos permanentes se habían constituido en torno a ellos ${ }^{16}$. Asimismo, exceptuando aquellos caminos que se encontraban conectados al eje vial Puerto Aysén - Coyhaique, es decir, al menos seis (Futaleufú, Palena, Lago Verde, Alto Rio Cisnes, Chile Chico, Cochrane), solamente se comunicaban terrestremente con Argentina y no con el "resto" de Chile. En este sentido, la conectividad de Patagonia Aysén previa dictadura no ocupa ni circula en el territorio nacional, sino que, por el contrario, sale de él.

Es por esto que el Comité Patria y Soberanía en 1966 estaba preocupado de que "de aquí a diez años más económicamente estas poblaciones estarán cada vez más integradas a la banda del este, si nosotros no hacemos nuestro propio camino longitudinal", de hecho, en esta época "la única ruta longitudinal terrestre" era la carretera n`40 argentina "cuyas ramificaciones hacia el oeste unen los centros habitados de nuestra región austral" (citado en Bascuñán, 1984: 95).

\section{Regionalización y "modernización" territorial en Aysén}

Antes de abordar el proceso de construcción de la Carretera Austral es necesario describir brevemente las principales características de la Regionalización en el entendido que en relación con esta reforma administrativa y territorial puede comprenderse más cabalmente la reestructuración impulsada por el camino austral durante la dictadura.

En los primeros años de dictadura las autoridades postularon que la proyección oficial de un Chile moderno dependía fundamentalmente de una "nueva estructuración del Territorio Nacional" (CONARA, 1976: 169). Desde este punto de vista, la antigua organización territorial había relegado

De norte a sur: Futaleufú (paso Futaleufú), Palena (paso Palena Carrenleufú), Lago Verde (paso Lago Verde - Las Pampas), Alto Río Cisnes, Coyhaique Alto (paso Coyhaique Alto), Balmaceda (paso Huemules), Ibáñez (paso Palavicini), Chile Chico (paso los Antiguos) y Cochrane (paso Roballos). 
a Chile a una condición de aislamiento y subdesarrollo que debía ser contrarrestada mediante un proyecto de "reconstrucción nacional" cuyo objetivo central sería "hacer de Chile una gran nación" (Gobierno de Chile, 1974).

Por un lado, imponer la "unidad nacional" normada según los principios de los grupos sociales al mando: Seguridad Nacional, autoritarismo, nacionalismo, catolicismo, y más tarde liberalismo económico y Estado subsidiario (Valdivia, 2010, 2015). En este sentido, desde los grupos golpistas, luego de "extirpar el cáncer marxista hasta las últimas consecuencias"17 quedaba la "tarea de reconstruir total, institucional y materialmente al país (...) cambiar la mentalidad de los chilenos" (Gobierno de Chile, 1974: 8).

Por el otro, eliminar y reemplazar cualquier resabio de la lógica territorial "de las cuencas" por un modelo uniforme y centralizado cuya base fuera la "integración territorial" (Chateau, 1978). En relación a esto último, la Declaración de 1974 exponía que el nuevo régimen "está ya abocado a la configuración de verdaderas zonas geográficas que reemplacen la artificial y anacrónica división político-administrativa de las provincias y departamentos que hoy nos rige, por una regionalización adecuada a la realidad chilena contemporánea" (Gobierno de Chile, 1974: 9).

De este modo, y sobre la base de un diagnóstico que consideraba grandes áreas del territorio nacional como despobladas, desconectadas e improductivas; la localización de amplios cordones de miseria sobre todo en los márgenes de las grandes ciudades proclives a la subversión; el escaso aprovechamiento de los recursos naturales y la "necesidad" imperiosa de modernizar al Estado chileno y racionalizar su territorio, la Regionalización se impuso desde los inicios del régimen autoritario, como una de sus obras representativas (Arenas, 2009).

Una de las principales características de esta reforma fue "definir no sólo la delimitación física de los territorios sino también la estructura de un nuevo sistema de autoridad" (Chateau, 1978: 151). Dicho de otra forma, suponía una nueva diagramación de los aparatos de Estado, administración pública y el espacio nacional, proyectándola "como un instrumento de Gobierno, de administración que sirve para alcanzar los objetivos de integración nacional, de la seguridad y del desarrollo en un marco más armónico, en términos geográficos diferentes de lo que ha sido la experiencia histórica chilena"18.

En este sentido, ante la constatación "de un país al borde de la desintegración física, económica, institucional y social", esta reforma debía asegurar "su integración nacional a través de la búsqueda de un mayor equilibrio entre el aprovechamiento de potenciales recursos naturales, la distribución geográfica de la población y la seguridad nacional" teniendo presente que "nuestra concepción del Estado es esencialmente unitaria y no federalista" ${ }^{\prime \prime}$.

Concretamente, esta reforma convirtió un país organizado en 25 provincias, 90 departamentos y 313 comunas a otro en 12 "regiones geográficas administrativas" y un área metropolitana con sus

\footnotetext{
Comandante en Jefe de la Fuerza Aérea, general Gustavo Leigh Guzmán, 11 de septiembre de 1973. Disponible en: https://www.youtube.com/ watch?v=3T1hZhu6Fm8

18 Junta de Gobierno. Acta n55, 27 de diciembre de 1973

19 A Junta de Gobierno. Acta n55, 27 de diciembre de 1973
} 
respectivas autoridades e instituciones. En efecto, cada uno de estos nuevos recortes territoriales quedó a cargo de una nueva autoridad creada y designada directamente por el Jefe de Estado quien delegaba atribuciones y funciones específicas. En consecuencia, y coherente con la lógica militarizada del gobierno, se constituyó una sola línea de verticalidad de mando mediada por escalones intermedios (intendentes, gobernadores, alcaldes).

En este sentido, de manera explícita CONARA afirmó que la reforma "no implica un debilitamiento del 'poder central', sino que por el contrario, el ejercicio del poder delegado, debidamente supervisado" (CONARA, 1976: 12). De esta manera robustecería un poder centralizado al jerarquizar las "decisiones y acciones que, siguiendo su propio pensamiento y superiores instrucciones, se manifestarán en resultados que apoyarán su gestión y acrecentarán su base de sostenimiento" (CONARA, 1976: 11).

Como obra "modernizadora", la Regionalización fue, por tanto, una reforma "totalizante y radical" pues procuró "crear una situación de irreversibilidad social mediante la desarticulación de las estructuras económicas, políticas, sociales, sindicales y culturales del país a fin de construir una nueva sociedad" (Boisier, 2010: 174), y, a la par de esa desarticulación, reforzó el carácter fuertemente centralizado y autoritario del Estado (Valdivia, 2015; Quiroz, 2019), con “una sola legislación, una autoridad legislativa única y un centro de decisiones ejecutivas supremas" 20 .

Según la Comisión, "la vigencia inmediata de las regiones para todo o gran parte del país tendría gravísimos riesgos y expondría al fracaso el régimen de descentralización que se propugna" (CONARA, 1976: 13), es por ello que, "considerando su especial situación geográfica y porque en ellas se han iniciado desde hace varios años experiencias de planificación del desarrollo y manejo de recursos a nivel regional" (CONARA, 1976: 13), se había escogido Aysén y otros cuatro recortes territoriales más como "región piloto" para introducir la reforma.

Ahora bien, en ninguna otra se insistió tanto como en este caso en la pronta necesidad de ser restructurada: "En el caso de la región de Aisén tiene especial significación, por cuanto es una de las provincias de más baja densidad de población e históricamente una de las más postergadas" (CONARA, 1976: 13) transformándose en ícono del nuevo proceso.

Uno de los principales mecanismos que confirmaron dicho estatus, fue la imposición de una "política de excepciones" tanto en lo tributario como en lo aduanero para así estimular un desarrollo que debía guiarse según las leyes de mercado. Estas normativas tributarias tendrían "el propósito de mitigar un tanto los obstáculos impuestos por la lejanía a los centros nacionales y la desarticulación física y funcional" (CONARA, 1976: 389-390). Un ejemplo claro de esto fue el decreto ley n 889 de 1975, de acuerdo al cual, por su condición de "zona extrema", Aysén debía ser sometido a un trato tributario y de incentivo especial "para hacerla compatible con la política económica general del Gobierno".

Complementario con este mecanismo, y bajo la lógica del Estado subsidiario, la asignación presupuestaria se transformó en la herramienta de intervención estatal más importante del perío- 
do. Este tipo de "planificación indicativa" fue llevada a cabo fundamentalmente mediante el Fondo Nacional de Desarrollo Regional (FNDR) creado en 1974 durante la implementación de la Regionalización para que el gobierno pudiera canalizar recursos presupuestarios para la materialización de programas y proyectos de desarrollo regional de interés nacional. Su administración quedó articulada a las nuevas instituciones, específicamente a los Gobiernos Regionales y a la Subsecretaría de Desarrollo Regional y Administrativo, del Ministerio del Interior.

De acuerdo a la Ley 19.175 que lo creó, y siguiendo los lineamientos de la Regionalización, el Fondo operaría como un programa de inversiones públicas (destinado al financiamiento de acciones en los distintos ámbitos de infraestructura social y económica de la región) cuyo propósito sería la compensación territorial, con el objeto de obtener un desarrollo armónico y equitativo.

En este sentido, si se analizan las asignaciones del FNDR como porcentajes del Producto Interno Bruto (PIB) regionales entre 1976 y 1979, Aysén aparece liderando la lista con un valor de 5.06\%, sobre un promedio nacional de $1.006 \%$ y la región más próxima, Magallanes, con $1.55 \%$. Asimismo, si se divide el presupuesto bruto recibido en el período 1976-1990 por cantidad de población por región, Aysén, se posiciona como la más favorecida: sobre un promedio aproximado por región para este período de 40 mil pesos per cápita, Aysén figuraba en la delantera con 165 mil (Franken, 2005: 14).

Además de indicar el lugar que tuvo Aysén en la política de Regionalización, lo significativo de estos datos es que cada año, parte importante del FNDR designado a la zona fue usado en costear la construcción de la Carretera Austral, constituyendo una de sus principales fuentes de financiamiento. Es decir, mediante este mecanismo, el gobierno hizo evidente su interés en el desarrollo de esta infraestructura en el proceso de "modernización" territorial (S/A, 1981). De ahí que el año 1984, el Subsecretario Ministerial de Transportes y Telecomunicaciones, Eliecer Aedo, opinara que, en relación a esta zona, el sector caminos "ha sido uno de los beneficiados con la regionalización", ya que gracias a la inversión realizada en el período "en estos diez años se han construido más caminos que en toda su historia pasada" 21

\section{Caminos para "verticalizar" Aysén}

En 1955 Augusto Grosse publica su Visión de Aysén donde entre otras cosas describe un trazado caminero tentativo que, según se reconoció durante el régimen autoritario (que lo volvió a editar el año 1974), inspiró notablemente la proyección del camino austral definitivo. Sin embargo, entre el camino proyectado por el explorador alemán y el concretado existirán dos grandes diferencias: por un lado, en su tramo central, la propuesta de 1955 hace pasar al camino por el litoral, específicamente por Puerto Aysén (entonces capital provincial). Por otro lado, la ruta de Grosse es particularmente sinuosa debido al recorrido que hace para unir localidades que entonces se encontraban únicamente vinculadas terrestremente con el lado argentino (Palena, Futaleufú, Lago Verde principalmente). 
En cambio, la ruta concretada por la dictadura no solo pasaría directamente por Coyhaique (nueva capital regional a partir de 1974), dejando relegado a Puerto Aysén a conectarse al "troncal" mediante un "ramal", sino que será relativamente más "recta" y simple que la sugerida por Grosse. Lo cual, según Vallaux, demostraría su potencialidad para el "apagamiento gradual de las diferenciaciones secundarias y la compresión más fácil de las tendencias centrífugas" (Vallaux, 1914: 307) o en otras palabras "uniformar" y "simplificar la geografía del Estado" (1914: 308) con el propósito, coherente con la Regionalización, de hacerlo más centralizado.

En términos concretos, es posible evidenciar la estructuración del eje de circulación vertical durante la dictadura mediante el vistazo a tres etapas distintas de la construcción de la Carretera Austral.

\section{a) $1976-1980$}

Como se ha mostrado, hasta por lo menos 1976, año en el que se retomaron oficialmente los trabajos de construcción, la circulación local era fundamentalmente transversal. Para comunicarse con otras áreas del país las opciones eran la vía marítima o la aérea, mientras que por tierra "el enlace con el norte del país se realiza a través del paso por Coyhaique Alto pasando por Argentina" (MOP, 1974: 189).

En los primeros años de dictadura, todavía la consolidación transversal era parte de la estrategia caminera. Según el Ministerio de Obras Públicas ésta consistía en "posibilitar la continuidad de los actuales recorridos de transporte carretero en territorio chileno, a través de nuevas rutas transversales" (MOP, 1974: 199). No obstante, al interior del organismo público ya se postulaba "la necesidad de construir lo que se ha dado en llamar Carretera Austral" (MOP, 1974: 201).

Más allá de dar cuenta del proceso de sedimentación del discurso "longitudinal" al interior del principal órgano gestor de la obra vial, lo importante en este caso es constatar que, según el MOP "La configuración que tiene la red caminera que se estudia para esta región es similar a la de Chile en general", es decir, "con una espina dorsal denominada en este caso Carretera Longitudinal Austral, a la cual concurren una gran cantidad de caminos transversales" (MOP, 1974: 201). Desde el punto de vista político y técnico, la construcción de esta nueva infraestructura caminera debía, por tanto, homologar la circulación y estructuración territorial patagónica a lo que se consideraba Chile, es decir, el territorio organizado y unificado en torno al eje longitudinal de la Carretera $\mathrm{Pa}$ namericana.

Los estudios definitivos para el longitudinal austral fueron encargados en marzo de 1976 por Pinochet al Cuerpo Militar del Trabajo y a la Dirección de Vialidad. A principios de agosto de ese año ya se había aprobado el proyecto que fue conocido en su momento con el nombre de Plan de Caminos de Penetración. El trazado, que debía ser entregado en 30 meses fue lo más "terrestre" y "simple" posible, no obstante, contaba con tres transbordos obligados $y$, en definitiva, se fue modificando con los años.

Por ejemplo, este primer diseño hacía pasar al camino por Caleta Tortel, poblado que, según la Regionalización, específicamente el decreto ley 1.230 de 1975, debía reemplazar a Cochrane como la capital de la Provincia de Capitán Prat. Sin embargo, no solo Cochrane sigue siendo capital 
provincial hasta el día de hoy, sino que en la década de 1980 se realizaron diversos estudios para mover la población de Tortel hacia el poblado de Puerto Yungay, al cual el camino arribó en 1996, mientras que a Tortel recién en 2003.

Coherente también con la nueva base que había configurado la Regionalización, el trazado fue dividido en distintos frentes de avance a cargo de entidades administrativas precisas. La sección norte, correspondiente a la X región, quedaría dividida en tres frentes: el tramo Puerto Montt - río Negro y Ralún - Cochamó a cargo de la Municipalidad de Puerto Montt; el tramo Leptepú a Chaitén a cargo de Municipalidad de Chaitén y, por último, el tramo Puerto Cárdenas a límite regional (confluencia río Frío y Palena) a cargo de la Unidad Fundamental (UF) del Regimiento de Ingenieros n4 'Arauco' de Osorno.

Mientras tanto, la sección que correspondía a la XI región, quedaría a cargo de la Intendencia Regional de Aysén en colaboración con las Municipalidades de Coyhaique, Aysén y Puerto Cisnes. De acuerdo al mismo proyecto, la prioridad la tendría el tramo Chaitén (X región) - Coyhaique (XI región) de $420 \mathrm{~km}$. Posteriormente debía ser extendido en dirección norte hasta Puerto Montt, para finalizar con la consolidación del tramo más austral, que debía unir Coyhaique con Puerto Yungay.

Si bien este esquema "municipal" no perduró, las faenas se siguieron ejecutando de manera "regionalizada". De este modo, en el caso de la X región, los trabajos pasaron a cargo del Cuerpo Militar del Trabajo (CMT) en conjunto con el Programa de Empleo Mínimo (PEM), mientras que en la $\mathrm{XI}$ región, los trabajos fueron realizados mediante contratos efectuados por empresas constructoras privadas con la Dirección de Vialidad dependiente del Ministerio de Obras Públicas.

Entre los avances más importantes de este primer período se encuentran: i) el tramo longitudinal desde Puyuhuapi a lago Risopatrón llevado a cabo a partir de 1976; ii) las exploraciones y trabajos de reconocimientos Ilevados a cabo por Vialidad tanto hacia el norte de la XI región donde tempranamente tomaron contacto con las faenas llevadas a cabo por el CMT, como hacia el sur en la zona del lago Vargas (Horvath, 1978; Polloni, 1982); iii) los trabajos (re)iniciados en 1979 en el eje Chaitén - Futaleufú, específicamente el tramo Puerto Ramírez a Futaleufú (Van Schouwen, 1996: 185); iv) el inicio, también en 1979, de los trabajos desde la localidad de La Junta en un trayecto longitudinal hacia el límite con la $\mathrm{X}$ región en el complicado sector de la cuesta Moraga; $v$ ) finalmente, la conexión transversal, en 1980, de Puerto Cisnes con Cisne Medio y su proyección al paso internacional de Alto Río Cisnes, para concretar su unión, antes inexistente, con el lado chileno.

En resumen, si bien es evidente el inicio de trabajos en varios sectores y la concreción de algunos de éstos, en esta primera etapa todavía hay un avance disperso y discontinuo en diversos frentes que no logra constituir un longitudinal propiamente tal. Es decir, para fines de la década de 1970, todavía la circulación en Patagonia Aysén "sale" por los caminos transversales de Chile hacia Argentina.

El conjunto de caminos que se van trazando por este territorio aun no puede ser considerado un sistema o una red. Mejor dicho, constituye una red vial en el lado argentino, pero no en territorio chileno donde todavía figura como un conjunto inconexo constituido de "líneas que unen puntos pero que no forman estructuras cerradas que puedan dar forma a circuitos" (Ávila, 2012: 148). 


\section{b) $1980-1985$}

Una segunda etapa, que podríamos situar en la primera mitad de la siguiente década, materializará los primeros avances en el sentido de verticalizar esta zona. En 1981 se logran progresos decisivos: por el sur se sigue avanzando lentamente en tramos (en su mayoría transversales) entre Coyhaique y Cochrane, sobre todo en el sector aledaño al lago General Carrera.

Pero por el norte se concretan los avances más significativos. En primer lugar, se terminan los trabajos en la piedra del Gato, uno de los sectores que presentó, junto con la cuesta Moraga y el portezuelo Queulat, las mayores dificultades debido a las condiciones particulares de la roca, los derrumbes y las condiciones climáticas. En segundo lugar, se completa la ruta entre portezuelo Queulat, La Junta y el límite regional, uniéndose de este modo el camino de la XI región al tramo que construía el CMT al lado norte del límite regional.

Gracias a la consolidación de estos tramos se completó, tras una inversión aproximada de 450 millones de dólares de la época, la primera etapa de construcción: $420 \mathrm{~km}$. longitudinales entre Chaitén y Coyhaique que fueron oficialmente inaugurados en febrero de 1982. Además, se llevó a cabo el estreno del camino transversal Futaleufú - Puerto Ramírez, y por último, las dos primeras villas fundadas al lado del camino: Santa Lucía y Vanguardia22.

Una vez culminada esta primera etapa de unión, se comenzó a hablar del Programa Red Vial Austral en el cual el camino longitudinal seguía teniendo prioridad, aunque se entendía como constitutivo de un sistema vial conformado además por caminos transversales, puentes y transbordadores (MOP, 1981-1982). Como tal, el proyecto pasaba a convertirse en una de las inversiones importantes del régimen, con financiamiento nacional (fundamentalmente el FNDR) y préstamos del Banco Interamericano de Desarrollo (MOP, 1984).

Según el Ministerio de Obras Públicas, en 1985 el total de kilómetros longitudinales eran 879,2, mientras que los transversales $1050 \mathrm{~km}$. Es decir, en términos absolutos, para esta época, la Red Vial seguía siendo predominantemente transversal, pero la superficie que se iba abarcando e integrando iba creciendo notoriamente en un sentido longitudinal.

Prueba de ello, mientras el trazado longitudinal había crecido en 614, 6 km., es decir, casi había triplicado su extensión, los transversales entre 1976 y 1985 habían crecido aproximadamente solo 219, 9 km. Asimismo, en términos porcentuales, a partir de 1976 es notoria la predominancia longitudinal por sobre la transversal (Fig.1).

22 Ruta austral. Presidente inaugura tramo de carretera. (23 de febrero de 1982). El Mercurio, p.1. 
Figura $\mathrm{N}^{\circ} 1$

Construcción de kilómetros de camino por año (1976-1985)

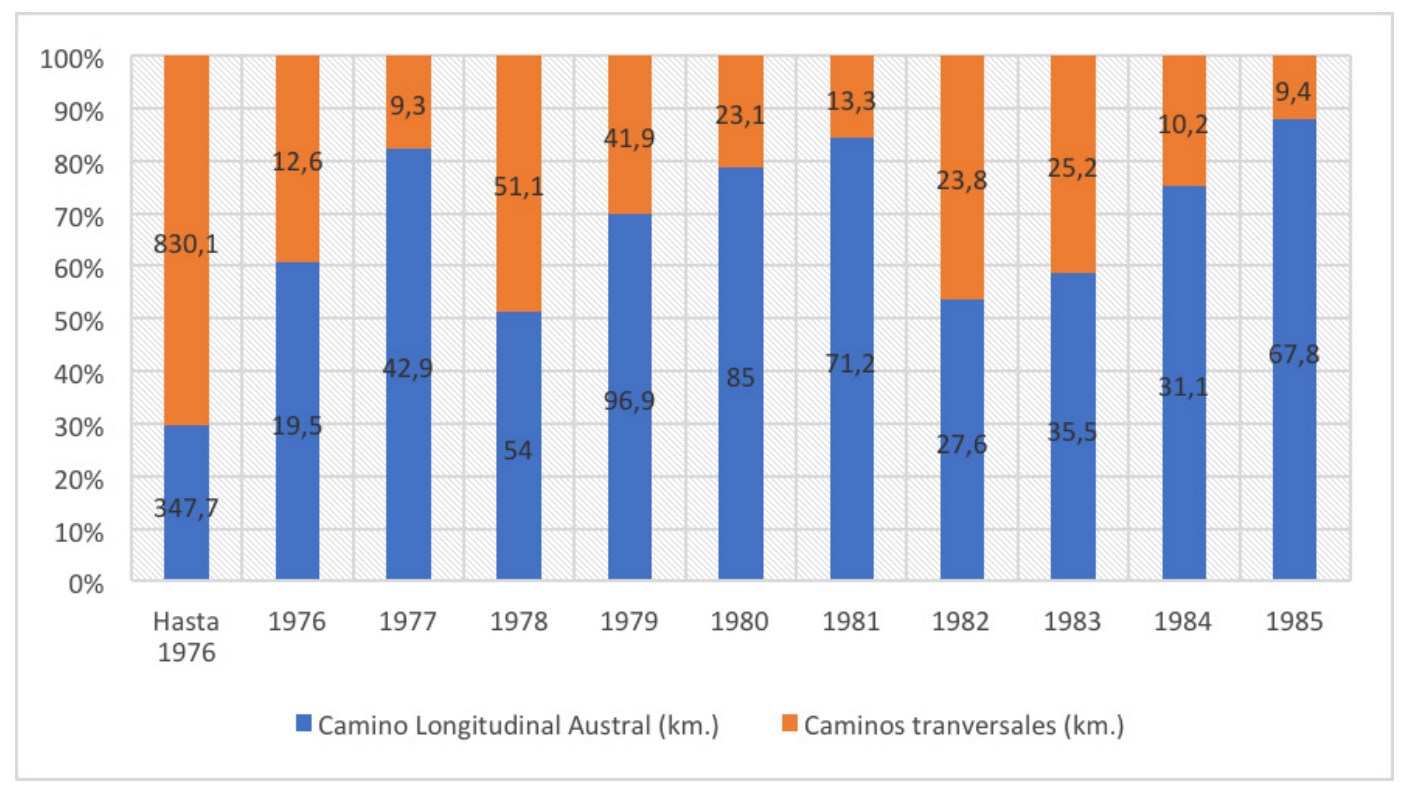

Fuente: Dirección de Vialidad. Ministerio de Obras Públicas. 1986 Camino Longitudinal Austral. Elaboración propia

De acuerdo a la Memoria del MOP del mismo año, la Red Vial consistía en aproximadamente 936 km. de camino longitudinal; $1050 \mathrm{~km}$. de caminos transversales más la variante (transversal) Ralún totalizando unos 2022 km. Con lo cual, según dicho anuario, en el período 1976 y 1986 se habían construido " $589 \mathrm{~km}$. de la Carretera Longitudinal Austral, $220 \mathrm{~km}$. de caminos transversales y 36 km. correspondientes a la variante Ralún” (MOP, 1986: 18), además de aproximadamente 3450 metros lineales de puentes, con un costo equivalente a US\$126 millones con valores de la época.

Más allá de cierta incongruencia en los datos, la constatación que resulta evidente e importante para nuestro planteamiento es que la red va creciendo longitudinalmente $y$, con ello, edificando una nueva lógica para circulación de Aysén que, según las autoridades, facilitaría "el ejercicio del Gobierno regional, provincial y comunal, el contacto directo de las autoridades con la población y una más eficaz solución de los distintos problemas políticos y administrativos" (Von Chrismar, 1986: 39), intensificando de esta forma la Regionalización en la zona austral.

De este modo, poco a poco, esta obra de ingeniería producía también su expresión política en la medida en que iba fijando un sentido hegemónico potencialmente normativo y estratégico al tránsito y los desplazamientos en una zona donde la circulación no necesariamente era escasa, sino que como hemos mostrado, transversal, es decir, contraria al sentido vertical que se buscaba imprimir uniformemente al país.

Luego de casi diez años de reiniciada la obra, se iba vertebrando "la espina dorsal" de las comunicaciones terrestres que debía unir Patagonia Aysén al "núcleo de cohesión del territorio de Chile 
continental, estimulando el desarrollo y la seguridad de esas áreas, consolidando y perfeccionando la unidad nacional y la integración física de Chile" (Von Chrismar, 1986).

\section{c) $1985-1989$}

La tercera y última etapa de este proceso recorre los últimos años del régimen y es quizás la más importante pues provee las primeras pruebas significativas de que se iba abarcando y articulando parte importante de Aysén, incrementando tanto los valores de conectividad como de accesibilidad (Ávila, 2012).

En este período se profundizaría en el programa Red Vial Austral que consistía en la extensión del trazado longitudinal y el ensamblaje de las vías transversales para "establecer una comunicación entre los centros poblados, tanto costeros como interiores, posibilitando además, el asentamiento de nuevos pobladores para propulsar la colonización y hacer más efectiva la posesión de estos territorios" (MOP, 1989: 52).

Obras significativas en esta etapa son la construcción del túnel en el sector El Farellón en el camino Puerto Aysén - Coyhaique, así como la pavimentación de parte de ese importante eje vial. También lo son los avances en el transversal Las Juntas - Lago Verde y en el Chile Chico - El Maitén. Sin embargo, sin duda que los hitos más expresivos tienen que ver con los avances longitudinales que tuvo el camino: la llegada a la ciudad de Puerto Montt por el norte y a Cochrane en el sur, ambas concretadas en 1988.

Según la Memoria del MOP de ese año, la red de caminos tenía 2.618 km., de los cuales 1.215 correspondían a caminos transversales, $1.25 \mathrm{~km}$. al longitudinal, $153 \mathrm{~km}$. a la variante Ralún, 4014 metros lineales de puentes más tres transbordos: Reloncaví (5 km.), Comau (40 km.) y Riñihue $(7 \mathrm{~km}$.$) .$

La inversión total en 1988 se estimaba en US\$ 198 millones de la época, financiado en un 50\% por el Fisco (FNDR y Fondos Sectoriales) y el otro $50 \%$ gracias a un crédito BID, representando aproximadamente un tercio de lo que habían costado las líneas 1 y 2 del Metro de Santiago (ODEPLAN, 1988: 1).

Por otro lado, de acuerdo al documento Factor de integración nacional. 15 años de progreso sostenido publicado en 1988 por el Ministerio de Obras Públicas para entonces la red tenía aproximadamente $2.400 \mathrm{~km}$. de caminos construidos, con 118 puentes definitivos (4.720 metros lineales) y tres transbordos que, en conjunto, ayudaban a la articulación de una superficie que representaba casi un sexto de todo el territorio nacional (Fig. 2).

Tal como muestra el gráfico organizado por períodos, durante los años de dictadura se había avanzado notoriamente en un sentido vertical. De hecho, más del 70\% de los caminos construidos en dictadura son longitudinales, lo que contrasta notoriamente con la construcción de longitudinales en las demás etapas que promedia el $20 \%$. De este modo, la Carretera Austral va convirtiéndose lentamente en el eje central de una "red compleja" que abarca y conecta verticalmente al territorio para reemplazar al modelo transversal precedente. 
Figura $\mathrm{N}^{\circ} 2$

Construcción de kilómetros de camino por período (1946-1987)

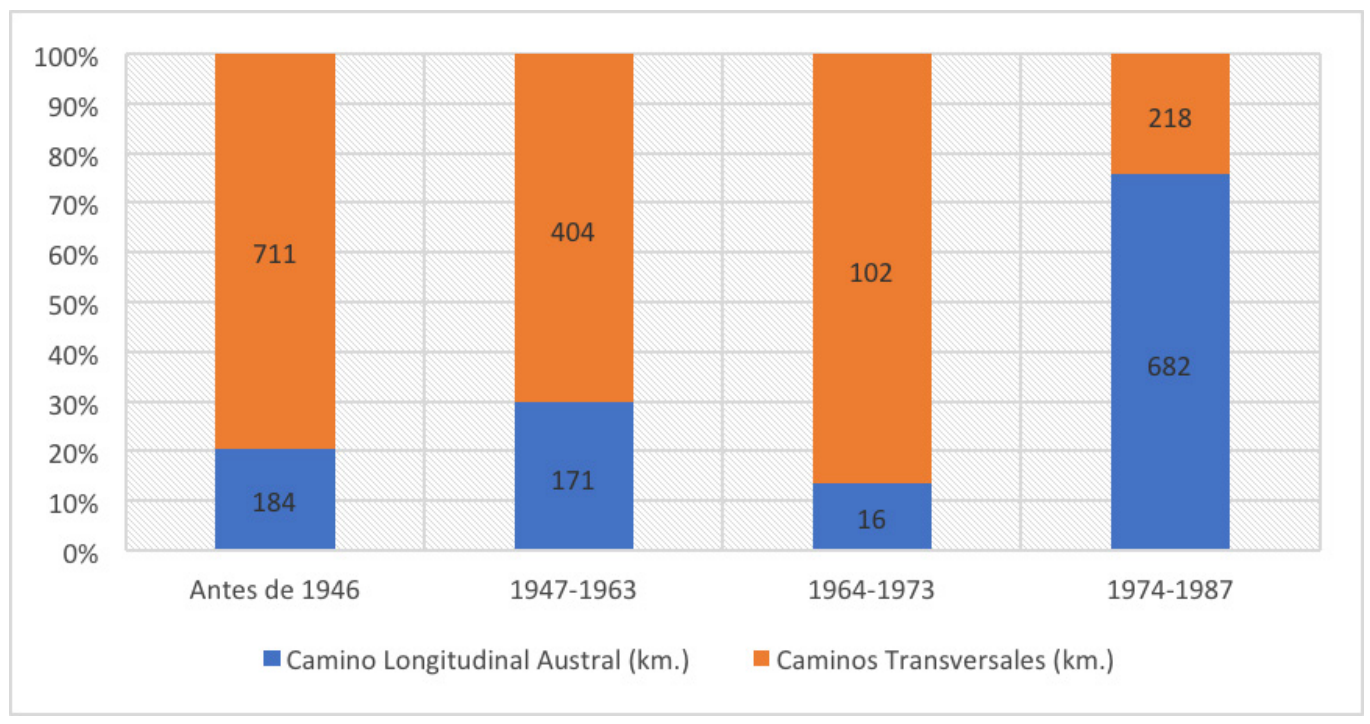

Fuente: Ministerio de Obras Públicas. 1988. Factor de integración nacional. 15 años de progreso sostenido 1973-1988. Santiago de Chile, Gobierno de Chile. Elaboración propia.

Este es el período en el que se hace evidente el salto cuantitativo más importante hasta entonces en relación a la (re)estructuración de la circulación patagónica. En efecto, a partir de esta época la circulación longitudinal puede abarcar largas distancias en territorio chileno, disminuyendo, poco a poco, la dependencia de las rutas argentinas, asimismo, la circulación entre poblados como Puerto Cisnes, Puyuhuapi y La Junta comienzan levemente a reemplazar el tránsito transversal y la comunicación exclusivamente fluvial o lacustre.

Además, este nuevo ordenamiento no se remite solamente a la cantidad de kilómetros y conexiones longitudinales construidas sino también, por un lado, al incremento en las alternativas viales de dirigirse de un punto a otro sin recorrer el mismo camino y, por otro, a una expansión de la red caminera que corre en paralelo al surgimiento de nuevos asentamientos (Ávila, 2012: 149).

Una red longitudinal como la que se iba concretando aumentaría, según el gobierno, el "flujo de las corrientes materiales y espirituales que dimanan del núcleo vital hacia los extremos del país, impidiendo con ello el "congelamiento" de las regiones septentrionales, donde la acción directa del Gobierno corría el riesgo de llegar muy diluida" es decir, permitiría "perfeccionar y consolidar la organización político-administrativa de la XI región, haciendo de la regionalización una realidad palpable" (García, 1989: 66).

De este modo, la Carretera Austral fue tramando "una arquitectura para la circulación" que fue produciendo e imprimiendo los efectos políticos y territoriales del autoritarismo y, junto a ello, constituyó un ejercicio concreto de soberanía en la medida que articuló, anexó e incluso creó (Villa Santa Lucía, Vanguardia, Villa Amengual) diferentes localidades y poblados en torno al longi- 
tudinal que antiguamente se excluían del proceso de circulación (política) del país, facilitando de este modo "la organización, ocupación y aprovechamiento del territorio austral, en una verdadera cruzada de "conquista" del propio espacio geográfico" (García, 1989: 64).

\section{Conclusiones}

La reorientación de la circulación austral durante la dictadura posee tres grandes hitos. El primero data de 1982 y consiste en la unión longitudinal (420 km.) de Chaitén, cabecera de la provincia de Palena, con Coyhaique, capital regional. Cada localidad constituía uno de los polos de los ejes viales más importantes de la zona antes de la construcción del longitudinal (Chaitén - Palena y Puerto Aysén - Coyhaique). De este modo, este hito fue relevante para la nueva lógica que se iba produciendo pues arremetió contra los dos principales ejes de circulación estructurantes para así desarticular su entramado horizontal que había dado existencia histórica a un territorio y unas formas de vida particulares organizadas en "cuencas" más o menos diversas e independientes la una de la otra, para conformar, en cambio, una unidad integrada terrestre y longitudinalmente.

El segundo hito, fue la unión longitudinal $(242 \mathrm{~km}$.) con tres transbordos incluidos, de la capital regional de Aysén (Coyhaique) con la capital de Los Lagos (Puerto Montt), pero todavía más importante, con la Carretera Panamericana, eje longitudinal estructurador del territorio nacional a través del cual era posible unirse con Santiago (capital nacional) y el "centro" del país. Este segundo avance inaugurado a principios de 1988 implica un acto de jerarquización y subordinación territorial que prioriza la unión con Chile (es decir, el territorio ya articulado verticalmente) antes que con el propio Aysén.

Por último, la expansión y consolidación de los caminos hacia el sur fue más lenta. A fines del período, la ruta había avanzado desde Coyhaique $337 \mathrm{~km}$. para conectar con Cochrane, no obstante el proyecto inicial tenía contemplado unir con Puerto Yungay, destino que se alcanzó recién en 1996.

En síntesis, esta secuencia expresa una red articulada "hacia adentro" y "hacia el centro". Desde el punto de vista de la circulación (política) los aproximadamente mil kilómetros longitudinales construidos en la época en Aysén fueron un mecanismo para disputar y extraer los flujos (de productos, de personas, etc) considerados oficialmente "chilenos", pero factualmente argentinos. La "chilenización", en este sentido, es aquella circulación zafada y sustraída del territorio argentino y en adelante encauzada en territorio chileno. En cierto modo, el longitudinal fue una forma de elevar una frontera en un área donde los Andes no opera como "límite natural".

Dentro del espacio nacional, la Carretera Austral activa un orden, por un lado, vertical en el sentido que se organiza y fluye no hacia el mar, ni hacia la frontera, sino en un sentido longitudinal, y, por otro, jerárquico en tanto el gran territorio que queda supeditado a dicho camino o línea troncal se orienta predominantemente hacia el "centro" del país, al que quedarán subordinadas las dinámicas locales (Amigo, 2017). Desde esta perspectiva, el agenciamiento de esta infraestructura resulta políticamente coherente con la Regionalización ya que, al igual que ésta, profundiza la "homogenización y verticalización del régimen político" (Quiroz, 2019: 333) de la dictadura, (re) definiendo sus proyecciones tanto en el nivel de las prácticas espaciales estratégicas vinculadas al 
manejo estatal (integración de Aysén al territorio nacional) como en el ámbito cotidiano (normalización de la circulación local). En este sentido, la construcción del camino austral fue mucho más que integrar puntos a través del territorio pues implicó la (re)configuración del espacio austral de tal modo que ha prolongado y estratificado la política del autoritarismo militar.

\section{Referencias Bibliográficas}

AMIGO, C. "No estamos lejos, allá están lejos. Construcción sociocultural del aislamiento". Perspectivas locales sobre aislamiento en Aysén: imaginario estatal y aislamiento como territorialidad. NÚÑEZ, A., ALISTE, E. \& BELLO, A. Imaginarios Geográficos, Prácticas y Discursos de Frontera: Aisén desde el texto de la nación. Coyhaique: Ñire Negro, 2017, p.239-262.

ARAYA, B. 2011. Crónica de Coyhaique. Coyhaique: I. Municipalidad de Coyahique, 2011.

ARENAS, F. El Chile de las regiones: una historia inconclusa. Estudios Geográficos, 2009, №266, p. 11-39.

ÁVILA, M. Políticas públicas y articulación del territorio: Desarrollo de la red vial en la región del Aysén Tesis para optar al Título Profesional de Geógrafo. Facultad de Arquitectura y Urbanismo. Universidad de Chile, 2012.

BAEZA, B. Fronteras e identidades en Patagonia central (1885-2007). Rosario: Protohistoria Ediciones, 2009.

BANDIERI, S. Historia de la Patagonia. Buenos Aires: Editorial Sudamericana, 2011.

BASCUÑÁN, I. Breve historia de Aysén y la Carretera Austral. Santiago de Chile: Estado Mayor General del Ejército Biblioteca del Oficial, 1984.

BENNETT, J. Vibrant matter a political ecology of things. Durham: Duke University Press, 2010.

BOISIER, S. Chile: la vocación regionalista del gobierno militar. EURE, 2010, №77, p.81-107.

BONELLI, C. \& GONZÁLEZ, M. ¿Qué hace un camino? Alteraciones infraestructurales en el sur de Chile. Revista Antropología, 2016, N³, p.18-48.

CHATEAU, J. Geopolítica y regionalización. Algunas relaciones. Santiago de Chile: FLACSO, 1978.

$\mathrm{CHOI}, \mathrm{M}$. More than human geographies of nature: toward a careful political ecology. Journal of the Korean Geographical Society, 2016, №5, p. 613-632.

CONARA. Chile hacia un nuevo destino: su reforma administrativa integral y el proceso de regionalización. Santiago de Chile: Ed. Gabriela Mistral, 1976. 
CRESSWELL, T. Towards a politics of mobility. Environment and planning D: society and space, 2010, N¹, p.17-31.

DALAKOGLOU, D. 'The road from capitalism to capitalism': Infrastructures of (post)socialism in Albania. Mobilities, 2012, Nº, p. 571-586.

DE LANDA, M. Viviendo al borde del caos. Conferencia dictada en el IX SITAC, Teoría y práctica de la catástrofe, enero 27-29 de 2011.

DE LANDA, M. A new philosophy of society: Assemblage theory and social complexity. New York: Continuum, 2006.

DE LANDA, M. A thousand years of nonlinear history. New York: Swerve Editions, 2000.

ELDEN, S. Governmentality, calculation, territory. Environment and planning D: society and space, 2007, No3, p. 562-580.

ESPINOZA, C. La Carretera Austral: la construcción de un concepto, 1976-2000. Revista Estudios Hemisfericos y Polares, 2016, Nº4, p.1-12.

FOUCAULT, M. El ojo del poder. Entrevista con Michel Foucault. Barcelona: Ed. La Piqueta, 1980.

FRANKEN, M. Análisis y evaluación de la distribución interregional y del cambio de ley del FNDR. Tesis para optar al grado de Magíster en Economía. Facultad de Ciencias Económicas y Administrativas, Pontificia Universidad Católica de Chile, 2005.

GARCÍA, G. Carretera Longitudinal Austral. La respuesta a un desafío. Revista Chilena de Geopolítica, 1989, N³, p.51-69.

GOBIERNO DE CHILE. Declaración de principios del Gobierno de Chile. Santiago, marzo 11 de 1974.

GREENHOUGH, B. More-than-human Geographies. En: LEE, R. et al. (Eds.). The SAGE handbook of Human Geography.Thousand Oaks: SAGE, 2014, p.94-119.

GROSSE, A. Visión de Aysén. Santiago de Chile: Instituto Geográfico Militar, 1955.

HARVEY, P. Y KNOX, H. The enchantments of infrastructure. Mobilities, 2012, N4, p. 521-536.

HENARE, A., HOLBRAAD, M. \& WASTELL, S. (Eds.). Thinking Through Things: Theorising Artefacts Ethnographically. London: Routledge, 2007.

HORVATH, A. Estudio preliminar de obras y reconocimiento del sector sur de Aisén. Trapananda, $1978, N^{\circ} 2$, p.116-134.

KREBS, R. Historia de la Carretera Austral. En: Fundación Presidente Augusto Pinochet Ugarte. La Carretera longitudinal Austral. Su impacto y proyección. Santiago de Chile, 1997, p. 19-41. 
LARKIN, B. The politics and poetics of infrastructure. The annual review of anthropology, 2013, NO1, p.327-343.

MANSILLA, A. Chile Austral: Aysén. Santiago de Chile: IGM, 1946.

MARTINIC, M. De la Trapananda al Aysén. Una mirada reflexiva sobre el acontecer de la Región de Aysén desde la Prehistoria hasta nuestros días. Santiago de Chile: Fundación Río Baker, 2014.

MASQUELIER, A. Road mythographies: space, mobility, and the historical imagination in postcolonial Niger. American ethnologist, 2002, N4, p.829-856.

MINISTERIO DE OBRAS PÚBLICAS (MOP). Memorias Ministeriales. Santiago de Chile, 1974-1989.

MINISTERIO DE OBRAS PÚBLICAS. Camino Longitudinal Austral. Santiago de Chile: El Ministerio, 1986.

MINISTERIO DE OBRAS PÚBLICAS. Ministerio de Obras Públicas: factor de integración nacional: 15 años de progreso sostenido: 1973 - 1988. Santiago de Chile: El Ministerio, 1988.

NARANJO, A. Chile y sus caminos. Geografía de las comunicaciones. Santiago de Chile: Lord Cochrane, 1971.

NÚÑEZ, A. La Formación y consolidación de la representación moderna del territorio en Chile: 1700-1900. Tesis para optar al grado de Doctor en Historia. Facultad de Historia, Geografía y Ciencia Política. Universidad Católica de Chile, 2009.

NÚÑEZ, A. El país de las cuencas: Fronteras en movimiento e imaginarios territoriales en la construcción de la nación. Chile, siglos XVIII-XIX. XII Coloquio Internacional de Geocrítica. Barcelona, 2012.

NÚÑEZ, A., ALISTE, E. \& BELLO, A. Imaginarios Geográficos, Prácticas y Discursos de Frontera: Aisén desde el texto de la nación. Coyhaique: Nire Negro, 2017.

NÚÑEZ, A., BAEZA, B. \& BENWELL, M. Cuando la nación queda lejos: fronteras cotidianas en el paso Lago Verde (Aysén - Chile) - Aldea Las Pampas (Chubut - Argentina). Geografía Norte Grande, 2017, N66, p.97-116.

ODEPLAN. La Carretera Austral y su impacto regional. Santiago de Chile: ODEPLAN, 1988.

PANELLI, R. More-than-human social geographies: posthuman and other possibilities. Progress in Human Geography, 2010, №1, p.79-87.

PASQUINO, P. Theatrum Politicum: The genealogy of capital - police and the State of prosperity. En: BURCHELL, G., GORDON, C. \& MILLER, P. (Eds.). The Foucault effect. Studies in governmentality. Chicago: The University of Chicago Press, 1991, p.105-108. 
PEÑA, M. Un camino llamado Chile: crónica del Cuerpo Militar del Trabajo. Santiago de Chile: Archivo del CMT, 1993.

POLLONI, J.A. Reportaje geopolítico a la Ruta Austral. Santiago: Guillermo Krum S, 1982.

QUIROZ, R. Geopolítica y revanchismo: notas del diseño territorial autoritario. En: NÚÑEZ, A., ALISTE, E. \& MOLINA, R. (Las) Otras Geografías en Chile. Perspectivas sociales y enfoques críticos. Santiago de Chile: LOM, 2019, p.323-345.

RICHARD, N. Aproximación al problema de los caminos, u odografía, en el Chaco y en la Puna contemporáneos. En: SENDÓN, P. \& VILLAR, D. Al Pie de Los Andes: Estudios de Etnología, Arqueología e Historia. Cochabamba: Itinerarios - ILAMIS, 2013, p.47-70.

RODRÍGUEZ, J.C., GISSI, N. \& MANDUJANO, F. Fronteras Internas y hegemonías predicativas en Chile: el caso de la Patagonia Austral. Chungará, 2018, N4, p. 633-650.

ROJAS, G. Chile Escoge La Libertad. Santiago: Editorial ZigZag, 2000.

ROSSETTI, F. De infraestructura a paisaje: La carretera austral como motor de resignificación. $A R Q, 2018, N^{\circ} 99$, p.86-95.

S/A. GEOCHILE 81': la regionalización actualizada. Santiago de Chile: Ercilla, 1981.

SAAVEDRA, S. \& MANSILLA, X. Tras las huellas de la carretera austral. Retazos de historia oral sobre conectividad en la Región de Aysén. Coyhaique: Ñire Negro Ediciones, 2014.

SHELLER, M. Y URRY, J. The new mobilities paradigm. Environment and planning A, 2006, №2, p. 207-226.

URRUTIA, S. Carretera Austral: ¿Integración o fronterización? Representaciones geopolíticas en torno a la ruta austral durante la dictadura militar (1973-1990). NÚÑEZ, A., ALISTE, E. \& BELLO, A. Imaginarios Geográficos, Prácticas y Discursos de Frontera: Aisén desde el texto de la nación. Coyhaique: Ñire Negro, 2017, p.239-262.

URRUTIA, S., NÚÑEZ, A. y ALISTE, E. "Naturaleza salvaje y agreste": los imaginarios de la naturaleza en la construcción del Camino Longitudinal Austral, Chile 1976-1990. Magallania, 2019, №2, p.55-72.

USHER, M. Veins of concrete, cities of Flow: reasserting the centrality of circulation in foucaults analytics of governmente. Mobilities, 2014, N4, p.550-569.

VALDIVIA, V. "iEstamos en guerra, señores!". El régimen militar de Pinochet y el "pueblo", 19731990. Revista Historia, 2010, N43, p.163-201. 
VALDIVIA, V. La democracia dictatorial pinochetista: regionalización y municipios. Avances del Cesor, 2015, N¹2, p.171-187.

VALLAUX, C. El suelo y el Estado. Madrid: Daniel Jorró, 1914.

VAN SCHOUWEN, G. Historia del Cuerpo Militar del Trabajo. Santiago de Chile: IGM, 1996.

VÁSQUEZ DE ACUÑA, I. Las vías de comunicación y transportes australes (siglos XVI al XX). Santiago de Chile, 1999.

VIRILIO, P. Velocidad y política. Buenos Aires: La Marca, 2006.

VON CHRISMAR, J. Trascendencia geopolítica de la Carretera Austral 'Presidente Pinochet'. Revista Chilena de Geopolítica, 1986, №1, p.35-43.

WHATMORE, S. Hybrid geographies. Nature, cultures, spaces. London: SAGE, 2002.

WHATMORE, S. Materialist returns: practicing cultural geography in and for a more than human world. Cultural geographies, 2006, №4, p. 600-609.

ZUNINO, D., GIUCCI, G. \& JIRÓN, P. Términos claves para los estudios de movilidad en América Latina. Buenos Aires: Editorial Biblos, 2017. 